\title{
Contribuição virtual na aprendizagem do estudante: um site interativo na disciplina de graduação genética animal
}

\author{
Virtual contribution to student learning: an interactive website in the animal \\ genetics undergraduate course
}

\section{Raimundo Bezerra da Costa ${ }^{*}$; ;ictor Barbosa Pereira ${ }^{2}$; Alysson Mariano de Sena $^{3}$; Fábio Ranyeri Nunes Rodrigues ${ }^{3}$; Ronaldo de Oliveira Sales ${ }^{4}$; Lívia Oliveira Bezerra da Costa Carpentieri ${ }^{5}$}

\begin{abstract}
Resumo. O interesse pela navegação virtual, demonstrado pelo estudante na própria sala de aula, amplia as possibilidades de utilização de diferentes recursos contribuintes ao ensino, a pesquisa e a extensão em genética e reprodução. Diante desse interesse constatado foi criada a plataforma eletrônica online "http://lagepeuece.wix.com/geneticauece"onde são disponibilizados materiais com conteúdos didáticos, vídeos, endereços eletrônicos e outros redirecionamentos. Ainda podem ser baixados arquivos que são utilizados enquanto as aulas vão sendo ministradas; também viabiliza contatar o professor ou o monitor através de um e-mail disponibilizado pelo site, o que agiliza a orientação do acadêmico quando necessário. Na construção do site foi feito o cadastro em uma plataforma na internet chamada WIX, seguindose da programação da página pelo WIX HTML5, editor disponibilizado pelo próprio WIX. Finalizando, foi feito o cadastro em outro site com tecnologia "nuvem" chamado MediaFire, onde foram elaborados os "uploads" dos materiais e vídeos disponibilizados pelo professor da disciplina. Essa nova sistematização organizacional na disciplina visa facilitar o ensinoaprendizagem e melhorar o desempenho do aluno no decorrer do curso.
\end{abstract} tecnologias.

Palavras-chave: interação virtual; internet; facilitação de aprendizagem; novas

Summary. The interest in virtual navigation, demonstrated by the student in the classroom itself, extends the possibilities of using different taxpayers' resources to education, research and extension in genetics and reproduction. Given this interest found, it was created the online electronic platform "http://lagepeuece.wix.com/geneticauece", in which there are materials available with educational contents, videos, e-mail addresses and other redirections. Files which are used along the classes can also be downloaded; it also enables the student to contact the professor or the monitor via an e-mail provided by the website, which speeds up the academic orientation when necessary. It was made the registration in an Internet platform called WIX, followed by the programming of the internet page by WIX HTML5, editor provided by WIX itself. Finally, it was made the registration in another website with the "cloud" technology, called MediaFire, in which the "uploads" of materials and videos provided by the professor of each discipline. This new organizational systematization in the discipline aims to facilitate the teaching-learning process and improve the student's achievement throughout the course.

Keywords: virtual interaction; internet; facilitation of learning; new technologies.

\footnotetext{
${ }^{1} \mathrm{LaGePe} / \mathrm{FAVET} / \mathrm{UECE}$

${ }^{2} \mathrm{LaGePe} / \mathrm{FAVET} / \mathrm{UECE}$

${ }^{3} / \mathrm{FAVET} / \mathrm{UECE}$

${ }^{4}$ DZ/CCA/UFC - ronaldo.sales@ufc.br

5 Colégio Jesus Maria José, Poços de Caldas-MG.

Autor para correspondência - * raibezcosta@ hotmail.com

Submetido em 28.11.2014; Aceito em 28.12.2014
} 


\section{Introdução}

Diante do interesse pela navegação virtual, demonstrado pelo estudante na própria sala de aula, é que foi criada a plataforma eletrônica online “http://lagepeuece.wix.com/geneticauec $e$ possibilitando apresentar diferentes recursos contribuintes para o ensino, a pesquisa e a extensão em genética e reprodução. Nesse endereço são disponibilizados materiais com conteúdos didáticos, vídeos, endereços eletrônicos e outros redirecionamentos. Ainda podem ser baixados arquivos que são utilizados enquanto as aulas vão sendo ministradas; também viabiliza contatar o professor ou o monitor através de um e-mail disponibilizado pelo site, o que agiliza a orientação do acadêmico quando necessário. Essa nova sistematização organizacional na disciplina visa facilitar o ensinoaprendizagem e melhorar o desempenho do aluno no decorrer do curso.
Esta é uma primeira experiência do Laboratório de Genética e Reprodução em Peixes Dulciaquícolas (LaGePe) que, inicialmente, direciona ações para a interação com os alunos da temática Genética Animal, público alvo prioritário. A disciplina é oferecida aos estudantes do $2^{\circ}$ semestre do curso de Medicina Veterinária, da Faculdade de Veterinária da UECE, a quem se destinam os conteúdos da plataforma, sendo por isso restringido o acesso de alguns temas ao público em geral.

Como vem se observando um franco crescimento na incorporação das novas tecnologias da informação na formação educacional, com os universitários utilizando cada vez mais as ferramentas digitais (KLAMMER et al., 2009), há toda uma intensão na disponibilização aos internautas da Internet interessados no tema, à medida que os assuntos forem sendo melhores organizados na referida plataforma. 
Pois, essas tecnologias e "http://lagepeuece.wix.com/geneticauec informações digitais de comunicação e” para facilitar a interação professortornam-se outra maneira de se fazer monitor-discentes e melhorar a educação, considerando os tempos qualidade do ensino na disciplina atuais e os novos espaços educacionais, Genética Animal da Faculdade de com papéis e formas inovadoras para Veterinária da UECE.

relacionamento de professores e alunos, o que gera oportunidade e resultados

\section{Material e Métodos}

Inicialmente foi feito o cadastro diversos (KENSKI, 2007). No caso em em uma plataforma de desenvolvimento questão valoriza-se o uso de softwares de sites na internet chamado WIX, educativos como ferramenta auxiliar ao seguindo-se da programação da página professor (RAMOS, 2012), com a no próprio editor disponibilizado pelo participação essencial do monitor da WIX, o WIX HTML5. A utilização do disciplina que amplia a dinâmica editor possibilita realizar as inclusões e interativa pela proximidade com $\mathrm{o}$ público-alvo.

alterações desejadas no site, como: adicionar links, fotos, abas, vídeos,

\section{Objetivo}

além de criar o endereço eletrônico do Criar uma plataforma eletrônica site:

online

“http://lagepeuece.wix.com/geneticauec

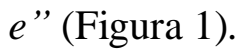




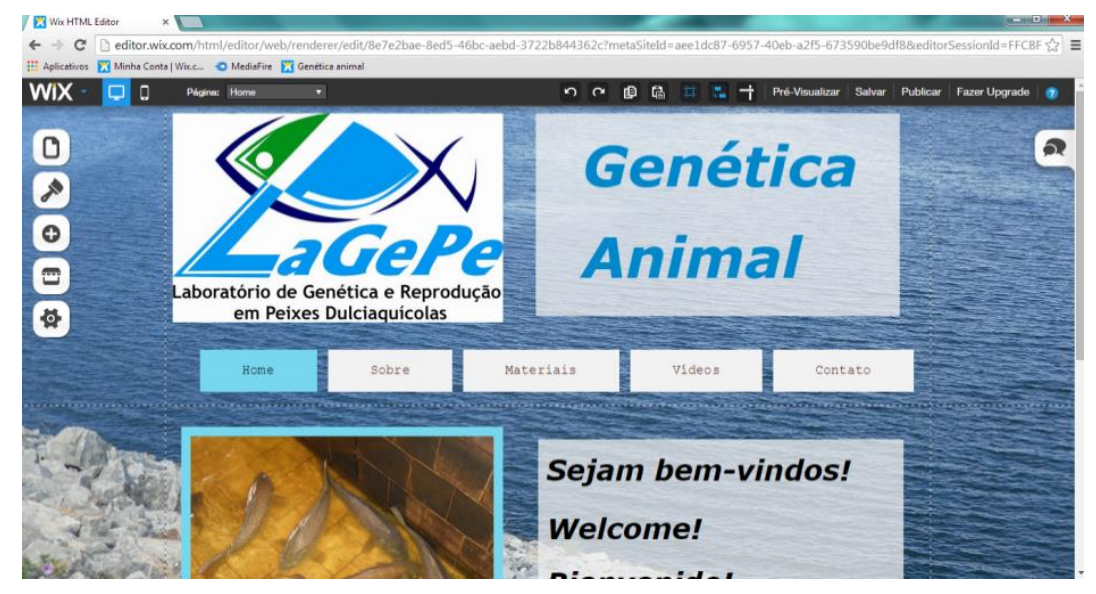

Figura 1. Tela principal do Site "http://lagepeuece.wix.com/geneticauece”.

Subsequentemente foi feito o cadastro em outro site com tecnologia "nuvem" chamado MediaFire, onde foram elaborados os "uploads" dos materiais e vídeos disponibilizados pelo professor da disciplina. Esse procedimento faz com que o site principal possa redirecionar os usuários para a plataforma "nuvem" que disponibiliza o "download" dos arquivos. Sendo, finalmente, feita a ligação entre o site principal e a "nuvem", apresentando os "links" de "download" da plataforma criada onde os usuários poderão obter os materiais que irão utilizar durante todo o período letivo (Figura 2); simultaneamente foi criada uma senha de acesso para a área dos "downloads", restringindo o site somente ao público alvo.

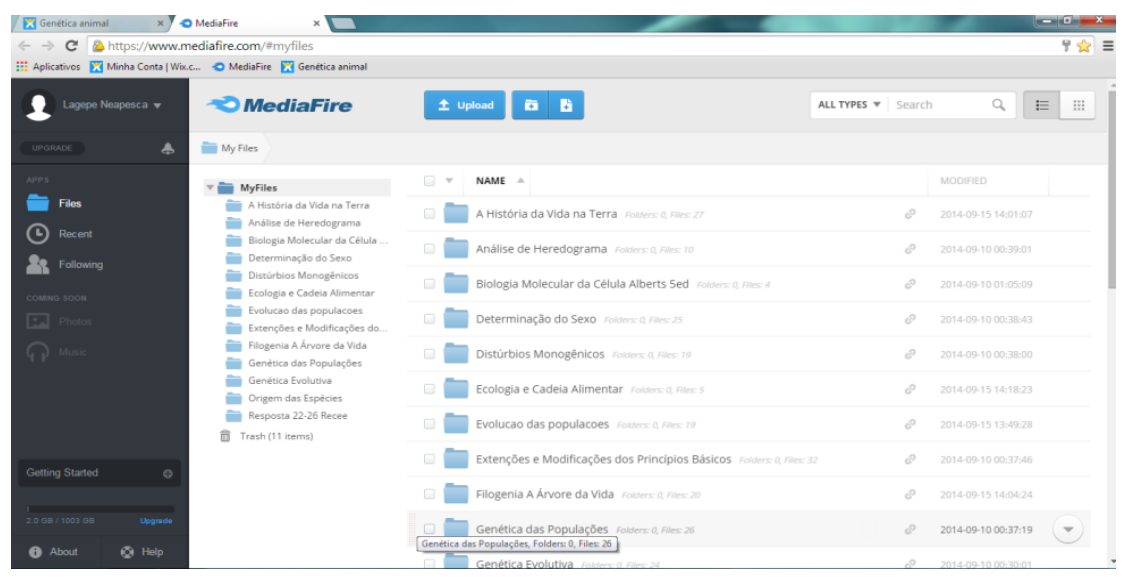

Figura 2. Tecnologia "nuvem", MediaFire, utilizada na elaboração dos "uploads" dos materiais e vídeos disponibilizados pelo professor da disciplina. 


\section{Resultados e Discussão}

A plataforma virtual, uma iniciativa do monitor da disciplina, foi apresentada aos discentes em sala de aula mostrando sua função, em termos de conteúdo, e utilidade como forma interativa para uma melhor aprendizagem. Em seguida foi fornecido o endereço eletrônico e a senha para acesso aos materiais. Assim, os alunos passaram a poder baixar os arquivos e assistir aos vídeos à medida que a disciplina ia sendo ministrada ao longo do semestre. Além disso, eles podiam contatar constantemente $\mathrm{o}$ professor ou o monitor da cadeira por email, através de um aplicativo disponível no site. Diferentemente da maioria das informações que se apresenta de forma desorganizada e dispersa postada na Internet, carecendo de um direcionamento em sua delimitação quanto a extensão e qualitativa de conteúdo tornando-a acessível à capacidade de assimilação dos discentes (KENSKI, 2003).

Dessa forma, com o site, buscase despertar o interesse do acadêmico e, com isso, surja a luz que falta para abrir seu próprio caminho de aprendizagem como um sujeito social e interativo (VYGOTSKY, 2003), beneficiando-se da interação da internet na formação educativa.

No site os alunos da cadeira adquirem os materiais gratuitamente e podem acompanhar o conteúdo da disciplina com todo o embasamento teórico das referências dadas pelo professor.

Como verificado em entrevista, o público alvo ao ser indagado da importância da plataforma, ficou demonstrada sua utilidade quanto ao conteúdo e direcionamento temático.

Contudo, durante as discussões surgiram sugestões para melhoria na quantidade, qualidade e dinamicidade 
dos conteúdos e uma maior divulgação com os próprios alunos da disciplina.

\section{Conclusão}

O site beneficia a todos envolvidos, melhorando a interação professor-monitor-discentes, de forma mais ágil e eficiente, economizando tempo, dinheiro (evitando xerox) e otimizando ações.

Torna clara sua eficácia no estímulo e orientação do monitor e dos estudantes, reduzindo o esforço do monitor durante o reforço no estudo com os alunos da disciplina, refletido na melhoria observada nos resultados avaliativos.

Uma interação desses estudantes com os colegas de outras disciplinas do curso poderá despertar esse mesmo interesse e haver uma propagação dessas ações beneficiadoras da aprendizagem.

\section{Agradecimento}

Pelo suporte financeiro proporcionado pelo CNPq, MPA, MCTI, MDA, MEC e MAPA, conforme Edital 81/2013.

\section{Referências Bibliográficas}

KENSKI, V.M. Tecnologias e ensino presencial e a distância. Campinas, SP: Papirus, 2003. (Série Prática Pedagógica).

KENSKI, V.M. Educação e tecnologias: O novo ritmo da informação. Campinas, SP: Papirus, 2007.

KLAMMER, C.S., CAMPOS, B.S., TAVARNARO, T. A relação do público universitário com a internet e a sua influência nos hábitos de leitura. Universidade Positivo, Curitiba-PR, 2009.

MediaFire. Disponível em <https://www.mediafire.com/>. Acesso em outubro de 2014.

RAMOS, F.P. A influência da Internet no processo de ensino/aprendizagem. Disponível em $<$ http://fabiopestanaramos.blogspot.com .br/2012/06/a-influencia-da-internet-noprocesso-de.html>. Acesso em dezembro de 2014.

VYGOTSKY, L.S. Pensamento e Linguagem; tradução Jefferson Luiz 
Costa et al., Revista Brasileira de Higiene e Sanidade Animal, v.8, n.4, p. 252-258, out-dez, 2014

Camargo; Revisão técnica José Cipola

Neto. São Paulo: Martins Fontes, 2003.

WIX. Disponível em

< $\underline{\text { http://www.wix.com/lplang/mobile-pt }}$

>. Acesso em outubro de 2014. 